\title{
Yucca schidigera e zeólita em alimento para gatos adultos e seus efeitos na excreção de minerais
}

[Yucca schidigera and zeolite in food for adult cats and its effects in mineral excretion]

\author{
J.P.F. Santos ${ }^{1}$, F.M.O.B. Saad ${ }^{2}$, N.C. Roque ${ }^{1}$, A.A. Aquino ${ }^{1}$, C.P. Pires ${ }^{1}$, L.F. Geraldi ${ }^{3}$ \\ ${ }^{1}$ Aluno de pós-graduação - Universidade Federal de Lavras - UFLA - Lavras, MG \\ ${ }^{2}$ Departamento de Zootecnia - Universidade Federal de Lavras - UFLA - Lavras, MG \\ ${ }^{3}$ Aluna de graduação - Medicina Veterinária - Universidade Federal de Lavras - UFLA - Lavras, MG
}

\section{RESUMO}

Avaliou-se efeito da inclusão de Yucca schidigera e zeólita (Clinoptilolita) em alimento comercial úmido para gatos sobre a aceitabilidade da dieta, produção fecal diária e porcentagem de águas nas fezes, e sobre o coeficiente de indigestibilidade aparente de cálcio, fósforo, magnésio, sódio, potásso, ferro e manganês. Foram utilizados 21 gatos adultos, sem raça definida, com quatro anos e meio de idade e peso médio de 3,56kg, distribuídos em sete tratamentos - dieta úmida denominada controle, e dietas controle com adição de 125, 250 e 375ppm de Yucca schidigera e 0,5\%, 0,75\% e 1,0\% de zeólita - em delineamento inteiramente ao acaso. Não foram observadas diferenças significativas na aceitabilidade das dietas, na produção fecal diária, na porcentagem de água nas fezes e no coeficiente de indigestibilidade aparente nos minerais avaliados $(\mathrm{P}>0,05)$. A inclusão dos aditivos que apresentam como função principal a redução de odor fecal pode ser realizada sem interferências sobre a saúde dos animais, do ponto de vista da nutrição mineral.

Palavras-chave: gato, aditivos, adsorção, odor fecal

\begin{abstract}
The objective of this study was to evaluate the effect of including Yucca schidigera and zeolite (clinoptilolite) in commercial wet food for adult cats, the acceptability of the diets, fecal production and average daily percentage of water in the stool and the coefficient of apparent indigestible calcium, phosphorus, magnesium, sodium, potassium, iron and manganese. We used 21 adult mongrel male and female cats, 4.5 years old and with an average weight of $3.56 \mathrm{~kg}$, distributed in seven treatments (wet control diet, control with the addition of 125, 250 and 375ppm of Yucca schidigera and 0, 5, 0.75 and 1.0\% of zeolite) randomly. Significant differences were not observed in the acceptability of the diets, fecal production and average daily percentage of water in the stool and the coefficient of apparent indigestible of minerals $(P>0.05)$. Thus, we noticed that the inclusion of additives which have the main function of reducing fecal odor can be inserted into food for adult cats without negative interferences on the health of animals ready for the sight of mineral nutrition.
\end{abstract}

Keywords: additive, adsorption, company animals, aroma faecal

\section{INTRODUÇÃO}

Com o crescimento da população de animais de companhia, o Brasil mostra-se como uma potência na produção de alimentos pet, com a instalação de diversas empresas e marcas, com as mais variadas formulações. Nesse sentido, surge a inclusão dos mais diversos aditivos, dentre eles a Yucca schidigera e a zeólita, cuja principal função é a redução do odor fecal (Lowe e Kershaw, 1997; Maia, 2008), de grande valia pela relação cada vez mais próxima entre os animais de companhia e os proprietários.

Recebido em 5 de novembro de 2010

Aceito em 6 de abril de 2011

E-mail: joao_paulo@zootecnista.com.br 
É de grande importância, porém, o estudo do impacto desses aditivos sobre a saúde dos animais, pois, quando se buscam publicações com Yucca schidigera e zeólita, diversos trabalhos são encontrados em animais de produção, principalmente aves (Çabuk et al., 2004), suínos (Colina et al., 2000) e vacas de leite (Grabherr et al., 2009), pela redução na emissão de amônia. Entretanto, poucos trabalhos avaliam o impacto desses aditivos sobre a digestibilidade de nutrientes em alimentos para gatos. E, quando se pensa em sua inter-relação com o processo digestivo de minerais, esses dados tornam-se ainda mais escassos.

Dessa forma, este trabalho foi realizado com o objetivo de avaliar o efeito da inclusão da Yucca schidigera e da zeólita natural (clinoptilolita) sobre a aceitabilidade do alimento, consumo de matéria seca, características fecais, produção fecal média diária e porcentagem de água nas fezes, e sobre o coeficiente de indigestibilidade aparente de cálcio, fósforo, magnésio, sódio, potássio, ferro e manganês.

\section{MATERIAL E MÉTODOS}

O experimento foi realizado no Centro de Estudos em Nutrição de Animais de Companhia no Departamento de Zootecnia da Universidade Federal de Lavras, em Lavras, MG, e foi aprovado pela Comissão de Bioética (019/2009) da instituição.
Os animais foram alojados, durante todo o período experimental, em gaiolas metabólicas de 60x50x70cm (altura x largura x profundidade), de arame galvanizado. Foram utilizados 21 gatos adultos, com peso de $3,56 \pm 0,78 \mathrm{~kg}$, sem raça definida, machos e fêmeas, com idade de quatro anos e meio, pertencentes à população permanente do gatil experimental. Os animais passaram por exame clínico, sanguíneo e coproparasitológico, que atestaram seu estado de saúde. $\mathrm{O}$ experimento foi dividido em dois períodos. Em cada período, os animais foram distribuídos em delineamento inteiramente ao acaso, constituído de sete tratamentos, considerando o animal como parcela experimental, totalizando 42 parcelas experimentais e considerando o período no modelo estatístico. Os tratamentos foram: dieta-controle; dieta-controle + 125ppm de Yucca schidigera em base da matéria seca; dieta-controle + 250ppm de Yucca schidigera; dieta-controle $+370 \mathrm{ppm}$ de Yucca schidigera; dieta-controle $+0,50 \%$ de zeólita (Clinoptilolita) em base de matéria-seca; dieta-controle $+0,75 \%$ de zeólita; dieta-controle $+1,0 \%$ de zeólita.

A quantidade de alimento fornecido baseou-se na fórmula de predição de necessidade energética do NRC (Nutrient..., 2006), dada por $100 \times \mathrm{PV}^{0,67}$. Os níveis de garantia e a composição da dieta comercial utilizada no experimento estão dispostos na Tab. 1.

Tabela 1. Composição do alimento comercial em base da matéria natural (MN) e em base da matéria seca (MS), obtido por meio de análise laboratorial

\begin{tabular}{lccc} 
Nível nutricional & $\begin{array}{c}\text { Informações do rótulo em } \\
\text { base de matéria natural } \\
(\%)\end{array}$ & $\begin{array}{c}\text { Informações do rótulo em } \\
\text { base de matéria seca } \\
(\%)\end{array}$ & $\begin{array}{c}\text { Análise em base de } \\
\text { matéria seca } \\
(\%)\end{array}$ \\
\hline Umidade & 78,0 & - & - \\
Proteína bruta & 8,0 & 36,4 & 34,8 \\
Extrato etéreo & 4,7 & 21,4 & - \\
Matéria fibrosa & 0,7 & 3,2 & 5,70 \\
Matéria mineral & 3,0 & 13,6 & 11,89 \\
Cálcio & 0,66 & 3,0 & 2,56 \\
Fósforo & 0,45 & 2,0 & 1,94 \\
Magnésio & - & - & 0,10 \\
Sódio & - & - & 1,15 \\
Potássio & - & - & 0,78 \\
Ferro & - & - & 0,05 \\
Manganês & - & - & 0,002 \\
Energia metabolizável & $967 \mathrm{kcal} / \mathrm{kg}$ & $4395,5 \mathrm{kcal} / \mathrm{kg}$ & $4452,7 \mathrm{kcal} / \mathrm{kg}$ \\
\hline
\end{tabular}

Composição: água, subprodutos animais, farelo de arroz, glúten de arroz, celulose em pó, óleo vegetal, fosfato de sódio, taurina, ácido ascórbico, fruto-oligossacarídeo, premix vitamínico mineral e premix micromineral transquelatado. 
A fase de adaptação foi constituída de cinco dias, nos quais os animais foram alojados nas gaiolas metabólicas, onde receberam água ad libitum e os respectivos alimentos experimentais disponíveis durante 24 horas do dia, controlados com base da necessidade energética. A fase de coleta constituiu-se de sete dias, nos quais os animais receberam o alimento no período da manhã, oito horas, e as sobras referentes ao dia anterior foram recolhidas, pesadas e acondicionadas em sacos plásticos e levadas ao freezer. A coleta de fezes, foi realizada duas vezes ao dia, pela manhã, oito horas, e à tarde, 17h. Em cada coleta, após a pesagem, o material foi acondicionado em sacos plásticos, em freezer. Passados os sete dias, as fezes e as sobras, pesadas e levadas à estufa de ventilação forçada, a $65^{\circ} \mathrm{C}$, por 72 horas, foram novamente pesadas, após atingirem equilíbrio com a temperatura do ambiente e moídas em moinho martelo.

As análises para a determinação de cálcio, fósforo, sódio, potássio, magnésio, ferro e manganês foram realizadas no Instituto Mineiro de Agropecuária, em Belo Horizonte, MG.
As determinações foram realizadas em espectrofotômetro de absorção atômica SpectraA 220 FS Varian, com lâmpadas de cátodo oco, com chama de ar/acetileno, conforme procedimentos recomendados por Cantle (1982). A determinação de matéria seca, proteína bruta, cinzas, fibra bruta e energia bruta, para a caracterização do alimento, foi realizada, de acordo com Silva e Queiroz (2002), no Laboratório de Pesquisa Animal da Universidade Federal de Lavras.

Os dados foram submetidos à análise de variância, utilizando-se o procedimento GLM do pacote estatístico SAS (SAS, 2004). Realizaram-se o teste de Shapiro-Wilk para normalidade dos resíduos e o teste de F máximo para homogeneidade do resíduo. Atendidas as premissas, as médias foram comparadas pelo teste SNK, a 5\% de significância.

\section{RESULTADOS E DISCUSSÃO}

Os dados de consumo de matéria seca, produção de fezes e porcentagem de água nas fezes são apresentados na Tab. 2.

Tabela 2. Consumo médio diário, em base de matéria seca, produção média de fezes na matéria natural e porcentagem de água nas fezes de gatos

\begin{tabular}{cccc}
\hline Tratamento & $\begin{array}{c}\text { Consumo médio (g/dia) } \\
\text { de matéria seca }\end{array}$ & $\begin{array}{c}\text { Produção de fezes } \\
(\mathrm{g} / \mathrm{dia})\end{array}$ & $\begin{array}{c}\text { Água nas fezes } \\
(\%)\end{array}$ \\
\hline Controle & 46,46 & 23,14 & 52,21 \\
125ppm YSE & 45,42 & 20,86 & 50,51 \\
250ppm YSE & 56,13 & 26,38 & 51,00 \\
375ppm YSE & 52,16 & 25,74 & 54,83 \\
0,5\% zeólita & 43,01 & 22,89 & 49,78 \\
0,75\% zeólita & 38,42 & 17,88 & 49,59 \\
1,0\% zeólita & 49,98 & 24,99 & 52,86 \\
CV (\%) & 23,86 & 28,30 & 9,95 \\
\hline P* & 0,1393 & 0,2466 & 0,5473 \\
\hline
\end{tabular}

YSE: Yucca sachidigera.

*Significância $\mathrm{P}<0,05$.

O consumo médio de matéria seca diário, a produção média de fezes e a porcentagem de água nas fezes não diferiram entre tratamentos $(\mathrm{P}>0,05)$, confirmando resultados apresentados por Shurson et al. (1984), Çabuk et al. (2004) e Ayasan et al. (2005), com animais monogástricos, e por Pond (1989), com ruminantes, ao trabalharem com zeólita ou extrato de Yucca schidigera. Estes dados vão ao encontro dos achados de Maia (2008) e Roque (2009), que avaliaram a palatabilidade dos aditivos nas doses mais elevadas (375ppm de Yucca schidigera e 1\% de zéolita) em cães e gatos adultos, respectivamente. Dessa forma, pode-se presumir que o efeito adstringente da Yucca schidigera, citado por Francis et al. (2002), e o aspecto argiloso das zeólitas não interferem negativamente na aceitabilidade dos alimentos pelos gatos. Este dado é de fundamental importância, do ponto de vista comercial, pois a 
aceitabilidade por parte dos animais é o primeiro ponto a ser avaliado pelo proprietário na escolha dos alimentos.

Avaliar os impactos dos aditivos sobre a qualidade fecal é de suma importância. Neste trabalho, tanto a produção de fezes (g/dia) como a porcentagem de água nestas não sofreram interferência $(\mathrm{P}>0,05)$ da adição da Yucca schidigera e da zeólita, corroborando os achados de Lowe e Kershaw (1997), que não encontraram diferença da inclusão da Yucca schidigera sobre a matéria seca das fezes de gatos. Çabuk et al. (2004) verificaram redução na matéria seca das excretas de frangos suplementados com 120ppm de Yucca schidigera e 2,5\% de zeólita; Ferreira et al. (2005) citaram aumento na porcentagem de água com a inclusão de aluminiossilicato. Para tais autores, esta água não é considerada livre, por estar associada à zeólita.

Outros autores, entretanto, demonstraram o efeito da suplementação da zeólita sobre o tratamento da diarreia, como Papaioannou et al. (2005), que citaram medicamentos baseados em zeólita para humanos com função de proteção da mucosa intestinal de microrganismos como a E. coli.

Para minerais, o termo digestibilidade é utilizado, atualmente, não pelo fato de os minerais serem digeridos, mas pelo fato de as fontes de minerais sofrerem processo de digestão. Dessa forma, na Tab. 3 podem ser verificados os coeficientes de indigestibilidade aparente de cálcio, fósforo e magnésio.

Tabela 3. Coeficiente de indigestibilidade aparente de cálcio, fósforo e magnésio em gatos

\begin{tabular}{clll}
\hline & \multicolumn{3}{c}{ Coeficiente de indigestibilidade aparente (\%) } \\
\cline { 2 - 4 } Tratamento & Cálcio & Fósforo & Magnésio \\
\hline Controle & 80,82 & 67,47 & 73,70 \\
125ppm YSE & 88,23 & 72,86 & 99,46 \\
250ppm YSE & 96,04 & 73,81 & 94,55 \\
375ppm YSE & 93,57 & 76,59 & 77,33 \\
0,5\% zeólita & 89,01 & 72,68 & 85,60 \\
0,75\% zeólita & 96,06 & 71,68 & 85,87 \\
1,0\% zeólita & 92,36 & 72,36 & 93,26 \\
CV (\%) & 14,53 & 15,32 & 18,15 \\
\hline P* & 0,7706 & 0,9532 & 0,5483 \\
\hline
\end{tabular}

YSE: Yucca sachidigera.

*Significância $\mathrm{P}<0,05$.

O coeficiente de indigestibilidade aparente de cálcio, fósforo e magnésio não diferiu $(\mathrm{P}>0,05)$ entre tratamentos. Estes dados vão ao encontro dos citados por Lima et al. (2008), os quais afirmaram que o destaque que a clinoptilolita vem ganhando em relação a outras zeólitas naturais pode ser explicado pela preferência desta pelos íons de $\mathrm{NH}_{4}$, comparados a outros cátions, tais como o $\mathrm{Ca}^{2+}$ e $\mathrm{Mg}^{2+}$. Shurson et al. (1984), ao trabalharem com clinoptilolita para suínos em crescimento, e Papaiannou et al. (2002), ao avaliarem a clinoptilolita para porcas, não encontraram efeito significativo destas sobre os minerais do plasma e sobre a concentração delas no fígado e nos rins.

Barros et al. (2003) verificaram adsorção do cálcio e do fósforo em dietas para frangos quando suplementados com zeólita. Entretanto, esses autores avaliaram a zeólita hidratada de sódio
(NaY) que apresenta capacidade adsortiva muito mais elevada que a clinoptilolita, pela sua baixa relação $\mathrm{Si} / \mathrm{Al}$. Destaca-se também que, pelo desequilíbrio de cargas, a clinoptilolita apresenta afinidade de adsorção por cátions frente aos ânions, o que explica o resultado encontrado neste trabalho com o fósforo.

Para a Yucca schidigera, os resultados também são similares aos de Omoruyi et al. (2006), ao não encontrarem efeito da saponina sobre a absorção de cálcio e magnésio em ratos, e aos de West et al. (1978), que não verificaram efeito da saponina da raiz da alfafa ou da Quillaja saponaria sobre a formação de complexo com o magnésio em estudo in vitro. Outra explicação para o ocorrido com o cálcio e o magnésio pode estar relacionada às baixas digestibilidades encontradas neste trabalho, em que o efeito dos aditivos pode ter sido mascarado. 
O coeficiente de digestibilidade aparente do fósforo $(27,5 \%)$ está muito próximo dos relatados de Malafaia et al. (2002), que trabalharam com suplementação de fontes de fibras para cães e obtiveram coeficiente de digestibilidade aparente de 32,5\% no tratamento controle. Já em relação ao cálcio, em um primeiro momento, este parece baixo (9,1\%). No entanto, uma das condições para absorção do mineral é o conteúdo deste na dieta (McDowell, 1992; Swenson e Reece, 1996). O alimento utilizado neste experimento continha 2,6\% de cálcio na matéria seca, ou seja, 0,06\% acima do máximo recomendado para cães pela
AAFCO (Association..., 2007), porém não é citada recomendação máxima para gatos. Partindo desse princípio, os dados de digestibilidade verificados neste trabalho são relativamente próximos aos citados no NRC (2006), com gatos de três anos, que apresentaram absorção aparente de 0\%-9\% em suplementação de $1,3 \%$ de fontes de cálcio.

Na Tab. 4, podem ser observados os coeficientes de indigestibilidade aparente de sódio, potássio, ferro e manganês.

Tabela 4. Coeficiente de indigestibilidade aparente do sódio, potássio, ferro e manganês, em gatos

\begin{tabular}{lcccc}
\hline \multirow{2}{*}{ Tratamento } & \multicolumn{3}{c}{ Coeficiente de indigestibilidade aparente (\%) } \\
\cline { 2 - 5 } & Sódio & Potássio & Ferro & Manganês \\
\hline Controle & 5,94 & 5,94 & 82,66 & 81,41 \\
125ppm YSE & 4,48 & 4,48 & 71,03 & 76,35 \\
250ppm YSE & 6,40 & 6,40 & 89,60 & 85,18 \\
375ppm YSE & 6,75 & 6,75 & 97,72 & 85,70 \\
0,5\% zeólita & 6,60 & 6,60 & 94,17 & 92,75 \\
0,75\% zeólita & 4,51 & 4,51 & 94,48 & 98,66 \\
1,0\% zeólita & 5,57 & 5,57 & 84,24 & 90,84 \\
CV (\%) & 37,09 & 41,77 & 20,40 & 17,18 \\
\hline P* & 0,1233 & 0,4970 & 0,4077 & 0,4923 \\
\hline YSE: Yucca sachidigera. & \multicolumn{4}{|}{} \\
*Significância P<0,05. & & & &
\end{tabular}

Não houve diferença $(\mathrm{P}>0,05)$ nos coeficientes de indigestibilidade aparente de sódio, potássio, ferro e manganês.

Papaioannou et al. (2002) não encontraram diferença no sódio e no potássio plasmático e em deposição no fígado e nos rins em suínos tratados com zeólita. De acordo com Lima et al. (2008), a seletividade da clinoptilolita segue o esquema: $\mathrm{Cs}^{+}>\mathrm{K}^{+}>\mathrm{NH}_{4}^{+}>\mathrm{Sr}^{2+}>\mathrm{Na}^{+}>\mathrm{Ca}^{2+}>\mathrm{Fe}^{3+}>\mathrm{Al}^{3+}>\mathrm{Mg}^{2+}$, sendo o íon $\mathrm{K}^{+}$o principal competidor com o íon $\mathrm{NH}_{4}^{+}$pelos sítios de troca, posto que ambos têm praticamente o mesmo raio iônico. Roque (2009), ao avaliar a redução de odor fecal de gatos alimentados com adição de zeólita, encontrou efeito das dietas com $0,5 \%$ e $0,75 \%$ do aluminiossilicato, o que pode ser explicado pelo efeito da clinoptilolita sobre a adsorção da amônia.

Dessa forma, pode-se presumir que a inclusão da zeólita é eficiente na adsorção da amônia, levando a blindagem à adsorção de demais cátions, conforme citado por Pond (1989), que não encontrou ação do aditivo sobre o cobre em ovinos. Entretanto, em animais alimentados com dietas com alta proteína, a inclusão do aluminiossilicato elevou o ganho de peso frente aos animais que receberam alta proteína e ausência de zeólita na dieta, o que pode estar relacionado à adsorção da amônia, proteção à intoxicação por ela e consequente blindagem à adsorção do cobre.

No presente trabalho, a ação da zeólita sobre a amônia e a consequente inibição à adsorção dos demais cátions da dieta adquirem maior importância por se tratar de um alimento úmido para felinos com alta porcentagem de proteína bruta (34,2\% em base de matéria seca).

Pelos dados de Lima et al. (2008), pode-se verificar que o ferro é um mineral de baixa afinidade com a zeólita. Dessa forma, os resultados encontrados no presente trabalho confirmam os encontrados pelos citados autores, nos quais não houve efeito da zeólita $(\mathrm{P}>0,05)$ sobre o coeficiente de indigestibilidade aparente do ferro. 
A inclusão de Yucca schidigera não apresentou efeito sobre o coeficiente de indigestibilidade aparente dos minerais. Entretanto, sua ação sobre eles não está completamente elucidada. Omoruyi et al. (2006) encontraram aumento na absorção de sódio e de potássio e redução na absorção de ferro na primeira semana de suplementação de saponina para ratos. Para Southon et al. (1988), a ação da saponina na indigestibilidade de minerais nos animais concentra-se em sua ação sobre os transportadores presentes na membrana, já que o composto apresenta ação marcante na permeabilidade da membrana.

\section{CONCLUSÕES}

A inclusão dos aditivos (Yucca schidigera e zeólita) nos níveis utilizados não afeta negativamente a excreção aparente dos minerais, cálcio, fósforo, magnésio, sódio, potássio, ferro e manganês, e não apresenta impacto indesejável sobre as características fecais, tais como volume excretado e porcentagem de água nas fezes. Dessa forma, os aditivos, que apresentam como função principal a redução de odor fecal, podem ser incluídos nos alimentos para gatos adultos, sem interferências negativas do ponto de vista da nutrição mineral.

\section{REFERÊNCIAS BIBLIOGRÁFICAS}

ASSOCIATION of American Feed Control Officials. AAFCO official publication. Atlanta: AAFCO, 2007. 512p.

AYASAN, T.; BAYLA, M.; CANOGULLARI, $S$. The effects of dietary yucca schidigera on egg yield parameters and egg shell quality of laying japanese quails (Coturnix coturnix japonica). Int. J. Poult. Sci., v.4, p.159-162, 2005.

BARROS, S.E.C.; CURVELLO, F.A.; JUNIOR-MACHADO, H.F. et al. Efeitos in vitro da zeólita NaY sobre fontes de cálcio e fósforo em rações para frangos de corte. Rev. Univ. Rural, v.22, p.89-95, 2003.

ÇABUK, M.; ALÇIÇEK, A.; BOZKURT, M. et al. Effect of yucca schidigera and natural zeolite on broiler performance. Int. J. Poult. Sci., v.10, p.651-654, 2004.
CANTLE, J.E. Atomic absortion spectrometry. New York: Elsevier Scientific, 1982. v.5, p.448,

COLINA, J.; LEWIS, A.; MILLER, P.S. A review of the ammonia issue and pork prodution. Nebraska: Nebraska Swine Reports. 2000. p.24-25.

FERREIRA, A.C.K.; ALFARO, D.M.; SILVA, L.C.C. et al. $\mathrm{O}$ uso de aluminiossilicato (SILVET ${ }^{\circledR)}$ como adjuvante na melhora do aspecto das fezes e desempenho das aves. Arch. Vet. Sci., v.10, p.117-122, 2005.

FRANCIS, G; KEREM, Z; MAKKAR, H.P.S et al. The biological action of saponins in animal systems: a review. Br. J. Nutr., v.88, p.587-605, 2002.

GRABHERR, H.; SPOLDERS, M.; FÜRLL, M. et al. Effect of several doses of zeolite A on feed intake, energy metabolism and on mineral metabolism in dairy cows around calving. $J$. Anim. Physiol. Anim. Nutr., v.93, p.221-236, 2009.

LIMA, R.M.G.; WILDHAGEN, G.R.S.; CUNHA, J.W.S.D. Remoção de íon amônia de águas produzidas na exploração de petróleo em áreas offshore por adsorção em clinoptilolita. Quim. Nova, v.31, p.1237-1242, 2008.

LOWE, J.A.; KERSHAW, A.S. The ameliorating effect of Yucca schidigera extract on canine and feline faecal aroma. Res. Vet. Sci., v.63, 61-66, 1997.

MAIA, G.V.C. Zeólitas (Clinoptilolita) e Yucca schidigera em rações para cães: palatabilidade, digestibilidade e redução de odores fecais. 2008. 85f. Dissertação (Mestrado em Zootecnia) Universidade Federal de Lavras, Lavras, MG.

MALAFAIA, M.I.F.R.; RIBEIRO, M.D. Consumo e digestibilidade aparente de minerais em dietas para cães contendo polpa de cítrus e folhas de alfafa. Cienc. Rural, v.32, p.863-867, 2002.

McDOWELL, L.R. Minerals in animal and human nutrition. London: Academic, 1992. 524p.

NUTRIENT requirements of dogs and cats. Washington, DC: National Academy of Science, 2006. 398p. 
OMORURY, F.O.; McANUFF-HARDING, M.; ASEMOTA, H.N. Intestinal lipids ans minerals in streptozotocin-induced diabetic rats fed bitter yam (Dioscorea polygonoides) sapogenin extract. Pak. J. Pharmac. Sci., v.19, p.269-275, 2006.

PAPAIOANNOU, D.; KYRIAKIS, S,C.; PAPASTERIADIS, A. et al. Effect of in-feed inclusion of a natural zeolite (clinoptilolite) on certain vitamin, macro and trace element concentrations in the blood, liver, and kidney tissues of sows. Res. Vet. Sci., v.72, p.61-68, 2002.

PAPAIOANNOU, D.; KATSOULOS, P.D.; PANOUSIS, N. et al. The role of natural and synthetic zeolites as feed additives on the prevention and/or the treatment of certain farm animal diseases: A review. Microporous Mesoporous Mater., v.84, 161-170, 2005.

POND, W.G. Effects of dietary protein level and clinoptilolite on the weight gain and liver and mineral response of growing lambs to copper supplementation. J. Anim. Sci., v.67, p.2772-2781, 1989.
ROQUE, N.C. Níveis de Zeólita (Clinoptilolita) e Yucca schidigera em rações para gatos. 2009. 95f. Dissertação (Mestrado em Zootecnia) Universidade Federal de Lavras, Lavras, MG.

SAS INSTITUTE. SAS User's guide: statistics. Ver. 5ed., SAS Inst., Cary, NC, 1985.

SILVA, D.J.; QUEIROZ, A.C. Análise de alimentos: métodos químicos e biológicos, 3.ed. Viçosa, MG: UFV, 2002.

SWENSON, M.J.; REECE, W.O.N. Dukes, fisiologia dos animais domésticos. 11.ed. Rio de Janeiro: Guanabara Kogan, 1996. 856p.

SHURSON, G.C.; KU, P.K.; MILLER, E.R. et al. Effects of zeolite a or clinoptilolite in diets of growing swine. J. Anim. Sci., v.59, p.1536-1545, 1984.

SOUTHON, S.; WRIGHT, A.J.A.; PRICE, K.R. et al. The effect of three types of saponin on iron and zinc absorption from a single meal in the rat. Br. J. Nutr., v.59, p.389-396, 1988.

WEST, L.G.; GREGER, J.L.; WHITE, A. et al. In vitro studies on saponin-mineral complexation. $J$. Food Sci., v.43, p.1342-1343, 1978. 